V.V. Budashko

\title{
INCREASING CONTROL'S EFFICIENCY FOR THE SHIP'S TWO-MASS ELECTRIC DRIVE
}

Purpose. For shipboard lifting and transporting machinery (LTM) with AC thyristor electric drives (ED) the problem of minimizing sway through the formation of the special law to change the principle of ED control over the lifting process is solved. Methodology. This goal was achieved through the following objectives: analysis of current studies on the reduction of the negative effects of load fluctuations, fixed on the suspension with variable parameters; determining the criteria to optimize the movement of the lifting mechanism and transfer control laws under which the load fluctuations are reduced; develop the methodology and experimental study of the main characteristics of the mobile model ED lifting mechanism with its load suspended from the perspective of both the parameterization of the control system (CS) as well as elements of ED. For realization of tasks in research methods of mathematical modeling of dynamic processes on the computer, structural methods of control theory, experimental studies in the laboratory setting have been used. Results. Based on analysis of current research can be concluded that the stability of the ED of LTM to the disturbing points provided coincidence zero electric coordinates and speed deviation diametric plane of the vessel from the vertical position. Criteria for optimizing CS used by the ED LTM mathematical description of its dynamics differential equations to the estimated coefficients derived from the functions of state variables. The experimental dependence of dynamic equations of motion of an object under the influence of disturbing forces in the coordinate plane allowed to parameterize characteristic equation to the form, providing the solution to sustainability since the motor shaft of LTM. The functional circuit of CS eliminates the aperiodic components in the control in compliance with the criteria of sustainability and quality of transients by applying all-range regulator coordinate characteristics of forcing overcoming the dead zone and increase electric resistance as the dynamic object. Practical value. Completion of the complex research may find practical application in the ED of ship's LTM, which will improve their performance, decrease between the operating and maintenance simple. References 15, figures 9.

Key words: ship's two-mass electric drive, control system, load sway, mathematical modeling, improvement, adaptability, stabilization.

На основании теоретических и практических исследований двухмассового электропривода судовой грузовой системы рефрижераторного судна, в работе решена научно-техническая проблема усовершенствования системы управления электроприводом, находящегося под разновекторными возмущениями. Результатом выполненных исследований является объединение уравнений, описывающих перемещения груза механизмом подъема рамки держателя паллет, в систему дифференциальных уравнений с коэффициентами, зависящими от колебаний судна. В теоретической части синтезировано математическую модель электромеханической системы механизма подъема, что позволило исследовать способы минимизации углов раскачивания рамки держателя паллет и временных интервалов, необходимых для стабилизации перемещения груза двухмассовым электроприводом механизма подъема, что дало возможность косвенно имплементировать сигнал, связанный со стохастической природой момента колебания судна, на координатную плоскость электропривода подъема. Такэже усовериенствован и исследован способ параметрической оптимизации математической модели электромеханической системы в функции угла раскачивания груза. На основании определения структуры и алгоритмов работы повымена эффективность системы управления двухмассовым электроприводом механизма подъема с точки зрения уменьщения времени стабилизации перемещаемого груза. Библ. 15 , рис. 9.

Ключевые слова: судовой двухмассовый электропривод, система управления, раскачивание груза, математическое моделирование, усовершенствование, адаптивность, стабилизация.

Introduction. There are a number of ship's lifting and transporting mechanisms (LTM) on which thyristor electric AC or DC drives are set: powerful overhead cranes, conveyors, high-performance column cranes. For such mechanisms tasks to minimize load sway can be effectively addressed through the formation of special laws for motor control, as the control system (CS) is built by a flexible technology. Currently, there are a number of solutions that reduce mechanical vibrations of the load [1]. These solutions are intended to limit accelerations in the transient and obtain a smooth change of the controlled parameter. These solutions include the use of master of intensity, utilization of filters on regulators outputs, the introduction of feedback by derivative controlled parameters, change of regulators gear ratios, regulation of starting and braking time [2]. When using the mentioned methods, significantly limit of load sway is achieved by significantly increasing the time of transients of load moving which reduces the performance of mechanisms. There is a need for the development of such control systems for LTM electric drives the use of which will most effectively limit load sway at high performance of the electric drive and the possibility of flexible mechanisms control using regression methods [3].

Investigations are carried out as a part of the research state budget work «Concepts, technologies and ways of improvement of ship power systems (SPS) of combined propulsive complexes (CPC)» of the National University «Odessa Maritime Academy» (state registration number 0114U000340).

Problem definition. For ship's LTM a special operating mode is such in which there is need for change a control principle during the load lifting process that connected primarily with permanent effects of environment on automatic control object (ACO). Moreover, when ACO is meant a subsystem formed for the following conditions: CS allows purposefully to change the controlled variables at some regular intervals; targeted adjustment of controlled variables is assessed by measuring in real time. Accident-free flow of various technological, industrial and transport processes can be achieved only when certain

(c) V.V. Budashko 
essential for these processes physical quantities are changed in some way. Task of respect the position is to provide practical change of the controlled value according to specified action when subjected to perturbation on the control process. In general, any automatic control system (ACS) can be build from two functionally complete subsystems: ACO and a unit of automatic control (UAC) interconnected in accordance with the control principle.

ACS performing anti-sway functions are divided into two main groups: with closed and disconnected control circuits [4]. The first ones are based on the feedback signal from the current load, angular deviation, the position of the electric drive elements and its speed measured by additional sensors. Systems with open circuit are using the warning of the fact of the controlled parameter out the limit and their operation principle is based on the attempt to eliminate the error before it occurs.

At present there are different approaches to mitigate the release of load that moves from the steady state. In [5] they apply an intellectual approach to the input of the signal generated to prevent the sway, the so-called compensation method with derivative proportional the controlled parameter. The same control principle using a neural controller based on the principle of compensation of the uncertainty was proposed in [6]. Control based on an observer was developed and tested in a real bridge crane [7]. In [8], at the investigation of two-dimensional model of the gantry crane with a PD fuzzy-controller they used detention of the feedback signal with compensation of the generated input signal of the error.

The aim of the paper is improvement of efficiency of the control process of ship's lifting and transporting mechanism electric drive as an electromechanical object, the most dependent on the position of the ship's plane to reduce the duration of operational downtimes.

To achieve the mentioned goal, in the work it is necessary to solve the following problems:

- to analyze current investigations on reducing the negative effects of load sways mounted on hanger with variable parameters;

- to define criteria of optimization of control laws of motion for mechanisms to lift and move in which the load sways are reduced;

- to develop a technique of experiment and investigate the basic characteristics of a moving model of the electric drive of the lifting mechanism with hanging on it the load from point of view of parameterization of both the ACS and UAC elements;

- on the basis of investigations to offer a functional circuit of the ACS for movement of lifting and transporting mechanism working in synergy, and show the positive aspects of the application of the CS followed by the prospect of their integration into any technological process associated with ship handling and operational modes changes.

The object of investigations is control processes for two-mass electric drive of the ship's handling systems.
The subject of investigation is structural circuits and transformation of automatic controls of ship's load lifting AC electric drives.

Methods of investigations. For realization of tasks in research we will use methods mathematical modeling of dynamic processes on the computer, structural methods of automatic control theory, experimental investigations in a laboratory setup.

At this stage should be noted that the destabilization of the LTM movement depends primarily on the mismatch of control processes inside the ACS with other technological process on the ship as the object influenced by the environment. And if we consider SPS of CPC at the dynamic positioning $(D P)$ mode, to do not take into account destabilizing factors is the right way to unresolved problems of load sway in general $[9,10]$.

Analyzing, for example, stability by Lyapunov, it is first need to pay attention to spatial equations describing the CS considering disturbing environmental factors affecting the CPC. That is, we can state necessity to improve Lyapunov methods because stability definition for a dynamic system, which is the ACS excluding the impact on it of the CPC behavior does not make sense [11].

There are many criteria for ACS stability but for CPC in general and in particular for the SPS as controlled objects a nonlinear transient structure that imposes restrictions on the application of these criteria for the time invariant nonlinear ACS for ship's characterized is characterized. Therefore, while the second Lyapunov method, on the other hand, infringes on versatility, and it is a prerequisite to analyze stability of nonlinear dynamic ACS, accurate solutions of its application is nothing to wait because they may be out of reach, and obtaining a successful result can be a daunting task, even - unfulfilled [12].

The next is the fact that for stationary linearized ACS inherent a problem of optimizing the gear ratios of regulators while respecting all electric performance of all electric drive as a part of the SPS of CPC. This is achieved by successive iterative reduction of gear ratios by the Lyapunov method typically using differential equations written in matrix form of linear inequalities to ensure the performance of electric drive [13]. Numerical examples show that the method is effective at identifying ACS controllers with too reduced gear factors that satisfy typical limitation of the performance, and as the main method, it can be extended to handle nonlinear ACS and controllers [14].

Fig. 1 shows a fragment of a handling systems of an upgraded refrigerated ship designed to guarantee parallel to the main on the upper deck technological process of pallet loading. 


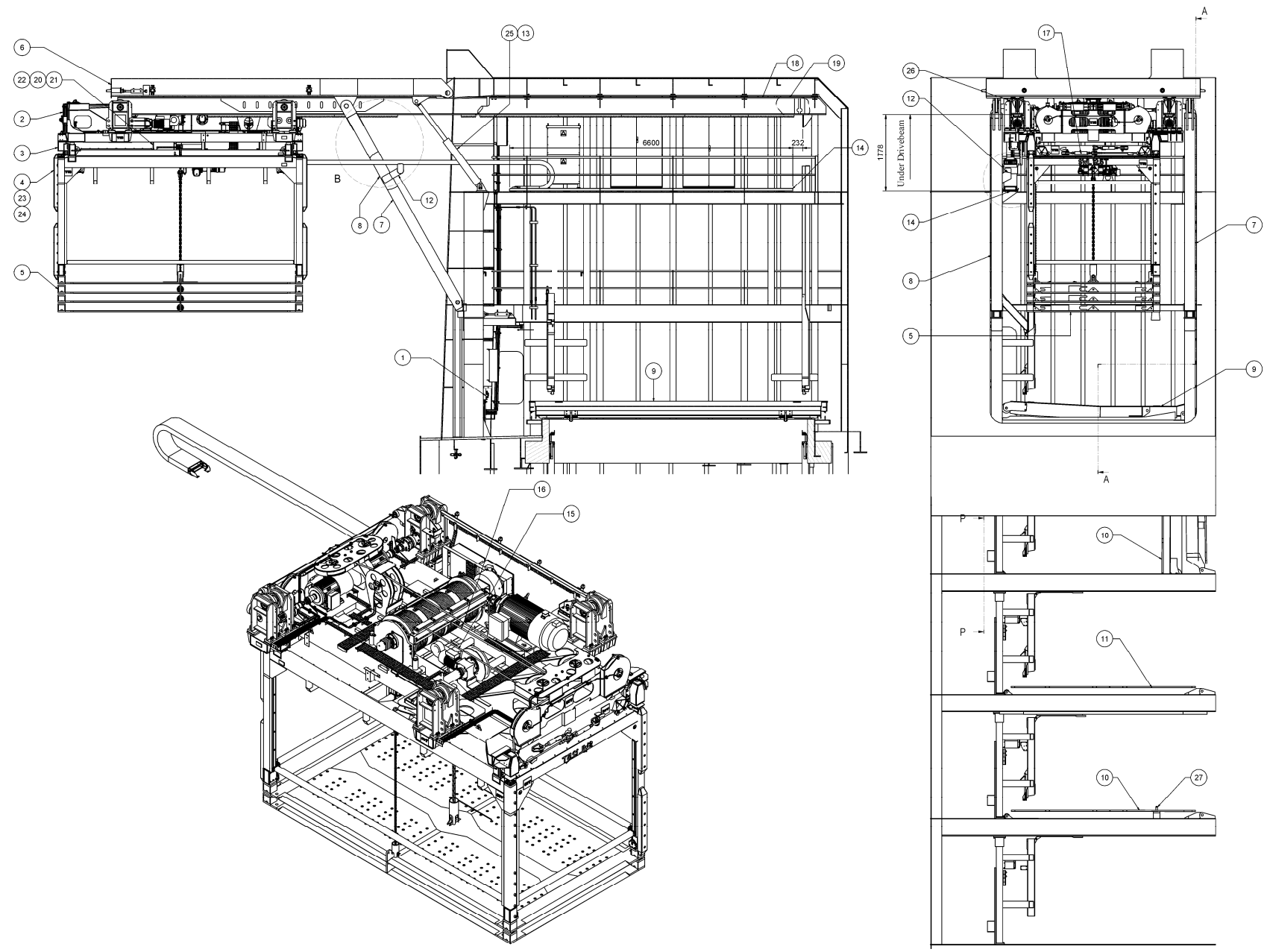

Fig. 1. A pallet handling system of a refrigerator ship: 1 - hydraulic installation; 2 - mounted metal trolley structure; 3 - mounted metal dispatcher structure; 4 - cage; 5 - additional low plate;

6-8 - side doors; 9 - manhole cover of the upper deck; 10 - manhole cover of the 2nd/4th deck; 11 - manhole cover of the 3rd deck; 12 - cable of the support network of left-hand assembly; 13 - cylinder bracket on the deck; 14 - tray for cable chain; 15, 16 - cable;

17 - hitch; 18, 19 - left and right trolley drives, respectively; 20 - power cable; 21 - cable fastening bracket; 22 - cable clamps; 23 - extra-heavy connector; 24 - cable input; 25 - hydraulic cylinder; 26 - anvil for sensor; 27 - axle; 28 - plate for blocking the internal trolley position; 29-31 - washer of the drive attachment Drivebeam; 32 washer; 33 - hexagonal self-locking nut; 34 - cylinder block head screw

The movement of loaded pallets is characterized by transient modes that depend on the behavior of the ship, so to describe it control laws for the lifting mechanism with smoothly variable acceleration were used. Identification of the ACS of the LTM for the pallet as stationary is possible with the assumption that the mass of the pallet is constant furthering its movement, so requirements are imposed to total time of the cargo operation.

The actual load oscillation is a very complex process that for practical calculations can be replaced by harmonic vibrational motion. The rate of vertical movement of the load is large enough. It should be borne in mind that the ship has the oscillatory motion with frequency usually lower than the frequency of oscillation of cargo. As a result, the speed of movement of the cable will be equal to the algebraic sum of the rates of movement of cargo and cable fastening points.

Solving the first and the second problems based on the equations of motion of a rigid body a system of equations for the determination of the relative vertical movement of the suspended frame of the pallet holder of the refrigerator ship's LTM (Fig. 2) was composed. Since such a parameter as ship's weight is decisive in the transient CPC and SPS in particular, the parameters of the loading electric drive can be neglected. In this regard account of ship's oscillations, change of the SPS and CPC parameters is generally carried out based on the use of socalled DMI-model models of ships depending on tonnage, disturbing factors and gear factors of regulators for all modes taking into account the ship transition to another operating mode. 

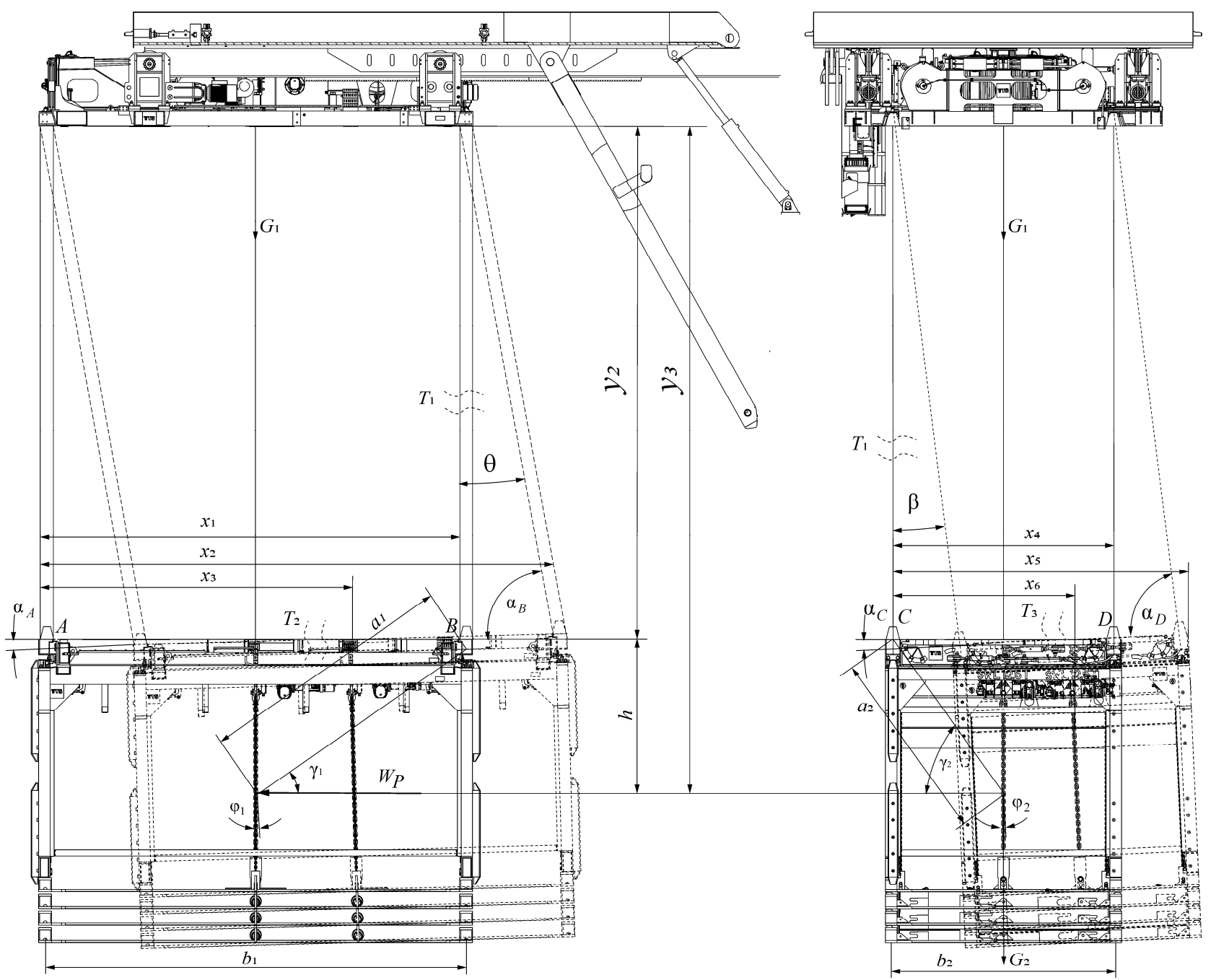

Fig. 2. A diagram of movement dynamics of the lifting mechanism: $m_{1}-$ lift carriage mass; $F_{T}-$ total driving force; $W_{P}-$ friction force of the carriage movement; $T_{1}$ - tension force of the perimeter cables; $T_{2}, T_{3}$ - tension forces of the transverse cables;

$G_{1}$ - gravity of the lift carriage; $G_{2}$ - gravity of the cargo restrainer (pallet); $G_{3}$ - gravity of the cargo (pallet);

$\varphi_{1,2}$ - carriage rotation angle; $\alpha_{A, C}, \alpha_{B, D}$ - angles between cargo and cables; $\theta, \beta$-deviation angles of corresponding cables from initial position; $h$ - vertical distance between points of cables fixing and cargo center of gravity; $b_{1,2}$ - distances between points of cables fixing; $a_{1,2}-$ distances between points of cables fixing and cargo center of gravity

$$
\left\{\begin{array}{l}
\ddot{x}_{1,4}=\frac{1}{m_{1}}\left(-T_{1,4} \times \sin (\theta, \beta)+F_{T}-W\right) \\
\ddot{y}_{1}=0 ; \\
\ddot{x}_{2,5}=\frac{1}{m_{2}}\left(T_{1,4} \times \sin (\theta, \beta)-T_{2,3} \times \cos \left(\alpha_{A}, \alpha_{C}\right)+T_{3,2} \times \cos \left(\alpha_{B}, \alpha_{D}\right)\right) \\
\ddot{y}_{2}=\frac{1}{m_{2}}\left(T_{1,4} \times \cos (\theta, \beta)-T_{2,3} \times \sin \left(\alpha_{A}, \alpha_{C}\right)-T_{3,2} \times \sin \left(\alpha_{B}, \alpha_{D}\right)-G_{2}\right) \\
\ddot{x}_{3,6}=\frac{1}{m_{3}}\left(T_{2,3} \times \cos \left(\alpha_{A}, \alpha_{C}\right)-T_{3,4} \times \cos \left(\alpha_{B}, \alpha_{D}\right)-W_{P}\right) \\
\ddot{y}_{3}=\frac{1}{m_{3}}\left(T_{2,3} \times \sin \left(\alpha_{A}, \alpha_{C}\right)+T_{3,2} \times \sin \left(\alpha_{B}, \alpha_{D}\right)-G_{3}\right) ; \\
\varphi_{1,2}=\frac{1}{m_{3}}\left(T_{2,3} \times a_{1,2} \times \cos \left(\alpha_{A}, \alpha_{C}-\gamma_{1,2}\right)-T_{3,4} \times a_{1,2} \times \cos \left(\alpha_{B}, \alpha_{D}-\gamma_{1,2}\right)\right)
\end{array}\right.
$$

where $T_{1}=k \times \Delta l_{1}+\beta \times \Delta i_{1}$ is the tension force of the perimeter cables; $k=\frac{E \times S}{l_{1}}$ is the cable stiffness coefficient; $E$ is the absolute module of elasticity of the hanger material; $S=\frac{\pi \times d^{2}}{4} \times c$ is the sectional area of the cable; $d$ is the cable 
diameter; $c$ fill factor of the cable section; $\Delta l_{1}=l_{1}-l_{10}$ is the perimeter cables expansion; $l_{1}$ is the perimeter cables length during movement; $l_{10}$ is the perimeter cables length in the equilibrium state; $\Delta i_{1}=\frac{\left(x_{1}-x_{2}\right) \times\left(\dot{x}_{1}-\dot{x}_{2}\right)+\left(y_{1}-y_{2}\right) \times\left(\dot{y}_{1}-\dot{y}_{2}\right)}{\sqrt{\left(x_{1}-x_{2}\right)^{2}+\left(y_{1}-y_{2}\right)^{2}}}-$ is the velocity of the perimeter cables length change; $\beta$ is the coefficient of energy losses; $T_{2}, T_{3}=k \times \Delta l_{2}, \Delta l_{3}+\beta \times \Delta i_{2}, \Delta i_{3}$ is the tension forces of the transverse cables; $\Delta l_{2}, \Delta l_{3}, \Delta l_{5}, \Delta l_{6}=l_{2}, l_{3}, l_{5}, l_{6}-l_{20}, l_{30}, l_{50}, l_{60}$ is the length change of the transverse cables; $l_{2}, l_{3}, l_{5}, l_{6}=\sqrt{\left(x_{2,5}-x_{A, C}, x_{B, D}\right)^{2}+\left(y_{2}-y_{A, C}, y_{B, D}\right)^{2}}$ is the length of the transverse cables during movement; $l_{20}, l_{30}$, $l_{50}, \quad l_{60}$ is the length of the transverse cables in the cargo equilibrium state; $\Delta i_{2}, \Delta i_{3}, \Delta i_{5}, \Delta i_{6}=\frac{\left(2 \times\left(x_{2,5}-x_{A, C}, x_{B, D}\right) \times\left(\dot{x}_{2,5}-\dot{x}_{A, C}, \dot{x}_{B, D}\right)+\left(2 \times\left(y_{2}-y_{A, C}, y_{B, D}\right) \times\left(\dot{y}_{2}-\dot{y}_{A, C}, \dot{y}_{B, D}\right)\right.\right.}{2 \times \sqrt{\left(x_{2,5}-x_{A, C}, x_{B, D}\right)^{2}+\left(y_{2}-y_{A, C}, y_{B, D}\right)^{2}}}$ is the velocity of the transverse cables extension; $G_{1}$ is the gravity of the cargo restrainer of the pallet; $G_{2}$ is the gravity of the cross bar; $m_{3}$ is the pallet mass; $\theta, \beta=\arctan \left(\frac{x_{1,4}-\dot{x}_{1,4}}{x_{2,5}-\dot{x}_{2,5}}\right)$ is the deviation angle of the perimeter cables from the initial position; $\alpha_{A}, \alpha_{C}=\arcsin \left(\frac{\left(x_{2,4}-x_{A, C}\right)\left(y_{B, D}-y_{A, C}\right)-\left(x_{A, C}-x_{B, D}\right)\left(y_{2}-y_{A, C}\right)}{b \times l_{2}}\right)$ is the angle between the cross bar and cargo; $\alpha_{B}, \alpha_{D}=\arcsin \left(\frac{\left(x_{2,4}-x_{B, C}\right)\left(y_{A, C}-y_{B, D}\right)-\left(x_{B, D}-x_{A, C}\right)\left(y_{2}-y_{B, D}\right)}{b \times l_{3}}\right)$ is the angle between the diameter ship's plane and cargo; $a_{1,2}=\sqrt{h^{2}+\left(\frac{b_{1,2}}{2}\right)^{2}}$ is the distance between the gravity center and cargo fixing points in the carriage; $h$ is the vertical distance between the center of gravity and points of cargo fixing in the carriage; $b_{1,2}$ are the distances between points of carriage fixing; $W_{P}=1000 \times \frac{1}{2} \times \rho \times \dot{x}_{3,6} \times c_{A} \times n \times b_{1,2} \times h$ is the friction force at the cargo movement; $\rho$ is the environment density; $c_{A}$ is the coefficient of the aerodynamic force account; $n$ is the overload capacity.

For the synthesis of the model of a two-mass electric lifting drive we used tools of three packages of the MATLAB system: basic Simulink (controlling and information channel with PID-regulator of speed) as well as specialized Sim-Power Systems (virtual blocks of the power channel) and Simulink Response Optimization (channel of optimization of built PID-regulators). In developing the model the recommendations and general approaches outlined in [12, 15] (Fig. 3) are taken into account.

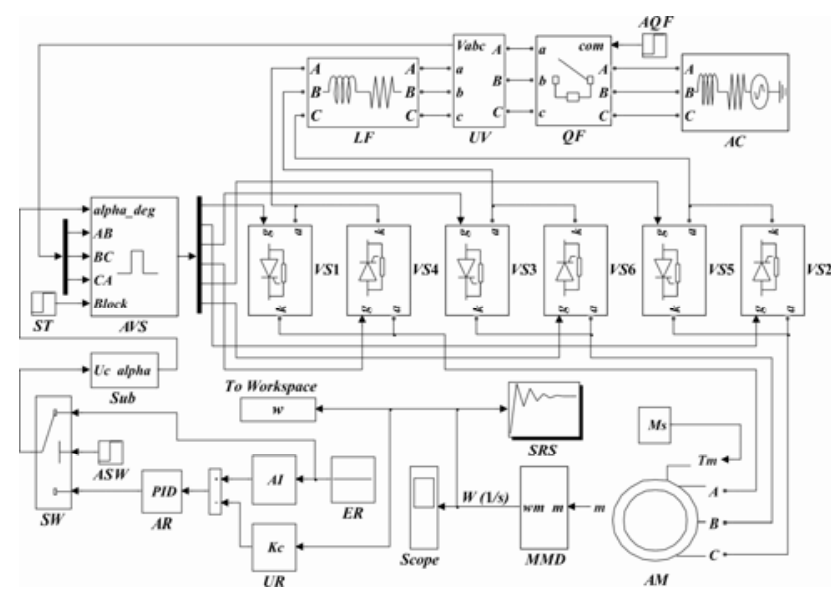

Fig. 3. Computer model of the experimental facility in Matlab Simulink
Below are functional purposes of block of the model, in parentheses are parameters that are introduced into the fields of windows of elements adjustment: $M-$ induction electric motor with squirrel cage (rated power, linear voltage, frequency, active resistance and inductance of stator and rotor windings, mutual inductance, moment of inertia, number of pole pairs); $M_{s}$ - block of load setting (the value of static torque); VS1...VS6 - thyristors of the thyristor voltage regulator (TVR) included two in each phase and connected back-to-parallel (resistance in the open and closed states, voltage drop on the thyristor); $A V S$ - a system of pulse-phase control (SPPC) (network frequency, width of control pulses); $S T$ - block of permission (zero signal) or prohibition (single) to the SPPC operation; $S u b$ - subsystem forming required range of angles to control TVR thyristors (minimum and maximum values); $A C$ - three-phase AC power network (linear voltage, frequency, resistance and inductance of the source); $Q F-$ circuit breaker (resistance in open and closed states); $A Q F$ - control unit for the circuit breaker (switch on by a single signal, switch off - zero); $U V$ - block of sensors of power supply voltage for synchronization of SPPC operation (linear or phase voltages); $L F$ - three-phase current limiting reactor for EMC of the electric drive and electric network (resistance and inductance); $E R$ - block of required speed setting (the value of the signal and the time of its 
coming); $A I$ - setter of intensity to limit the acceleration of the drive (rate of increase of the signal of the set speed); $A R$ - PID-regulator of speed (proportional, integral and differential components, limitations of output signal); $U R$ - speed sensor to form a negative feedback (gear ratio); $M M D$ - block of controlled parameters extraction (speed and torque of the motor); $S R S$ - block of optimization of parameters of PID-regulator of speed (required parameters of the transient); Scope - oscilloscope for visualization of monitored parameters (number of inputs, modeling time); To Workspace - block of speed values output to the working area for further processing (controlled parameter indicator); $S W$ - key switching the model operation modes (numerical value of the functioning setup); $A S W$ - key control block (single input signal commutes top input, zero - bottom).

To process discrete numerical values of the experimental speed characteristics taken from the working area of the MatLab system and to determine factors of the ACS transfer functions tools of the package Labview were used. In our case the following values of factors were obtained: $b_{0}=6.2334 e^{9}, a_{1}=8726.8, a_{2}=0.98763 e^{7}$, $a_{3}=4.31234 e^{8}-$ at approximation by the transient characteristic of the $3^{\text {rd }}$ order; $K=18, a_{0}=8.345 e^{-7}$, $a_{1}=0.04567-$ at approximation by the transient characteristic of the $2^{\text {nd }}$ order.

The next step of investigations is determination of dependences to calculate the components of PIDregulator of speed by the gradient-less Powel method in which computation of derivatives is performed by simplified difference formulae which provides increased speed of optimization. Appropriate formulae can be obtained using classical technique similar systems with subordinate regulation of coordinates taking into account the dependences (1).

For the third-order approximately, ignoring the part of the polynomial of the denominator of the third degree:

$$
\begin{aligned}
& K_{P}=\frac{a_{2}}{a_{C} T_{\mu} b_{0} K_{C}}, K_{I}=\frac{a_{3}}{a_{C} T_{\mu} b_{0} K_{C}}, K_{D}=\frac{a_{1}}{a_{C} T_{\mu} b_{0} K_{C}}, \\
& K_{P}=\frac{a_{1}}{a_{C} T_{\mu} K K_{C}}, K_{I}=\frac{1}{a_{C} T_{\mu} K K_{C}}, K_{D}=\frac{a_{0}}{a_{C} T_{\mu} K K_{C}},
\end{aligned}
$$

In the presented expressions $K_{\mathrm{C}}$ is the coefficient of the negative feedback by speed; $T_{\mu}$ is the time constant taking into account operating speed of the TVR thyristors; $a_{C}$ is the adjustable parameter of the speed circuit (standard value equals to 2). Calculated components of the PID-regulator of speed are input to the adjustment window of the block $A R$ parameters. At modeling of the closed system TVR-IM we commutate the lower input by the key $S W$. To obtain results of modeling without regulator's parameters optimization it is necessary to start the process by the button of the model main window.

The main requirements for electric drives of lifting mechanism based on the above analysis are: ensuring start of lifting without an unacceptable shock in the cable, providing cable tension before the lifting, exclusion of re- peated impact of the lifted load by ship. These requirements can be achieved in two ways.

The first way. The electric drive has two basic speeds, low for the cable tension at the beginning of movement $(0.25-0.35 \mathrm{~m} / \mathrm{s})$ and high for the load lifting equal to the average rate of the ship's lifting in the direction of the load lifting or exceeds it. The high speed is of $1.5-2 \mathrm{~m} / \mathrm{s}$ depending on the wavelength of the ship's oscillation. The transition of the electric drive to high speed the control system should carry out when the load will be in the lowest point of the ship's slope at the stretched cable. Here, the load begins to lift along with the beginning of the lifting of the ship and, after a slack of the cable will be chosen, continues to lift at a constant speed until the time of the lift of the ship in the direction of the load movement is over and if the following condition met

$$
v_{l} \geq 1.3 \frac{h_{0}}{T_{l}},
$$

where $v_{l}$ is the speed of the load movement, and

$$
1.3 \frac{h_{0}}{T_{l}} \approx 1 \text {. }
$$

The adjustment range of speeds for lifting mechanisms operating under this method should be $1 / 6 \div 1 / 8$. Obviously, these mechanisms should be used for loads of limited mass (less than $15 \mathrm{t}$ ) because at the increasing of power of the electric drive the inertia of the system increases.

The second way. Loading mechanism has a special design with a cable or a mechanical differential and two motors. One of the motors is traction, and another - speed. Traction motor provides selecting the initial cable slack with speed of $0.2 \div 0.25 \mathrm{~m} / \mathrm{s}$, and then it switches to maximum speed. At the same time high-speed motor switches on connected to the mechanism by overtaking clutch and click. Speed motor should ensure removing the cable at speed of at least $2 h_{0} / T_{l}-0.5 \mathrm{~m} / \mathrm{s}$ and acceleration time when removing the cable idle no more than $T_{l} / 10$. After reaching the top point of lifting the ship the speed motor stops and traction one continues to run at maximal speed. This speed should be at least $0.5 \mathrm{~m} / \mathrm{s}$ to avoid dynamic impact even when the ship lifting height will be $40 \%$ above the previous height. Thus, the range of speed control in this system is $1 / 2 \div 1 / 3$, and the speed motor can be performed without the speed control device. System with high-speed motor can be used for lifting any loads up to several tens of tons. The disadvantage of such systems is the complexity of the mechanism and low reliability due to the fact that at fault of the handling device of the speed motor the drop of cargo is possible.

Ships during loading and unloading operations feel longitudinal and transverse pitching, period and amplitude of which depend on the degree of agitation, and the design features of ships. Overload operations are carried at vibrations only when they have reasonable parameters. The sum of vertical displacement of the ship is within $2 \div 5 \mathrm{~m}$ at the period of pitching $6 \div 12 \mathrm{~s}$. The condition for safe landing of the load or its overload is to maintain a 
constant distance $H_{0}$ between the place of loading and load at disconnected load lifting mechanism. The movement of cargo relatively the ship's deck is described by the complicated formula:

$$
h_{0}=f\left(h_{1}, h_{2}, h_{3}, t_{1}, t_{2}, t_{3}, \varphi_{\text {max }}, \varphi, \varphi_{0}, l\right),
$$

where $h_{1}, h_{2}, h_{3}$ are respectively the amplitudes of the vertical ship's displacement and the distance by height from the LTM center of gravity to the ship's center of gravity; $t_{1}, t_{2}, t_{3}$ are the periods of corresponding ship's orbital movements; $\varphi_{\max }, \varphi, \varphi_{0}$ are the angles corresponding the ship's lurch with pallet restrainer, restrainer inclination and phase shift of the ship's pitching; $l$ is the length of the pallet restrainer boom over the ship's board.

At such a complex movement of the load regarding the ship's deck to maintain the stability $h_{0}$ the mechanism is complemented by a special compensating device as to provide tracking using electric drive is practically impossible. The implementation of such devices permits to use for the described mechanisms usual electric drives complemented by the necessary devices for ultimate protection and locking that prevent the movement of the load in the danger zone with no surveillance. There are several ways of reliable compensation of relative movement of ships and cargo. The common feature of these methods is the use of mechanical power sensor of automatic system.

Results of investigations. Fig. 4 shows the charts of the speed of the electric motor using calculated coefficients of the PID-regulator for standard setting by unidentified transfers function of the third (Fig. 4,a) and the second (Fig. 4,b) order.

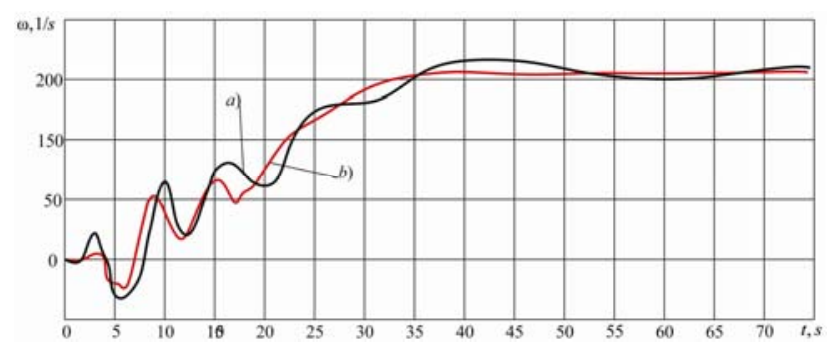

Fig. 4. Charts of the electric drive velocity at the system approximation by transfer functions of the second $(a)$ and the third $(b)$ order

To adjust the components of PID-regulators by optimizing the transients it is necessary to run the model by the button of the settings window of the optimization block SRS (Fig. 3). After optimization we obtain the following results (Fig. 5,a,b).

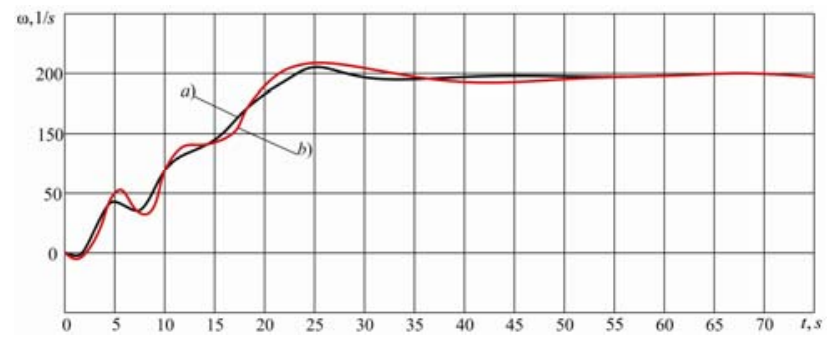

Fig. 5. Charts of the electric drive velocity at optimization by speed for the second $(a)$ and the third $(b)$ order
In order to eliminate vibration processes in the electric drive by adjusting electric control algorithms that ensure the stability of the process of movement of cargo and to confirm the theoretical part, experimental investigations were carried out on a laboratory facility the principal diagram of it is shown in Fig. 6, and external view in Fig. 7.

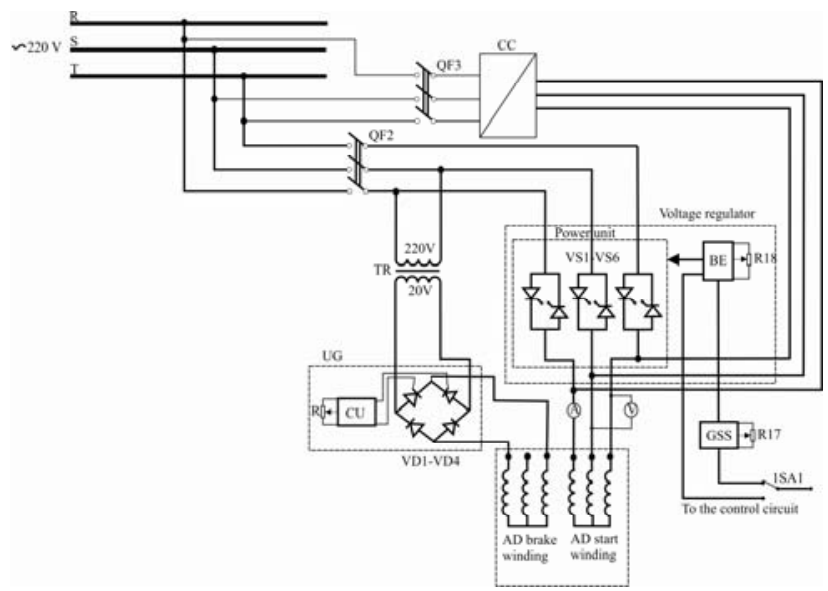

Fig. 6. Principal diagram of the laboratory facility: $Q F 2, Q F 3-$ circuit breakers, $C C$ - frequency converter; $A D$ - doublewinding induction motor; $T R$ - step-down transformer; $B E$ - electronic block; $G S S$ - starting signal generator; $U G-$ rectifier; $V D 1-V D 4$ - rectifier diodes to supply the braking coil;

$V S 1-V S 6$ - power thyristors; $R$ - resistor setting the braking torque; $R 18$ - resistor setting voltage on the $I M$ windings; $1 S A 1$ - control methods switch

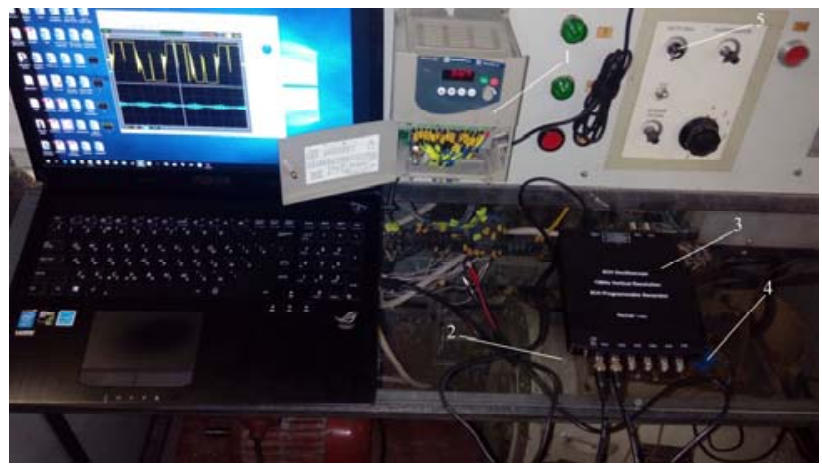

Fig. 7. External view of laboratory facility: 1 - frequency converter; 2 - double-winding IM; 3 - oscilloscope; 4 - current sensor; 5 - load current adjustment

Fig. 8, 9 show graphs of transients before and after optimization of electric drive control laws on the basis of above theoretical material.

The results of mathematical modeling in MatLab Simulink and experimental investigations on laboratory facility confirmed the basic theoretical principles initiated.

Conclusions. In the work solution of actual scientific and technical problem of improvement of efficiency of control process of electric drive of ship's lifting mechanism is carried out. The essence of the research is theoretical generalization of disturbing effects on the movement of the loaded pallet in the most dependent on 
the position of the ship plane that essentially define the non-linearity of electromechanical object behavior, thus reducing duration of operational downtimes.

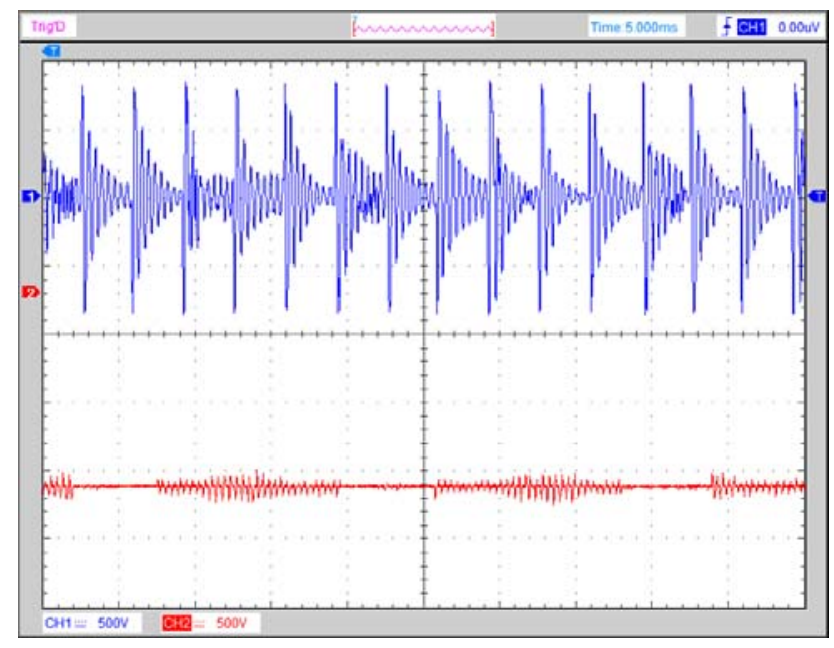

Fig. 8. Dependences of the rotating frequency and current of the $I M$ before optimization

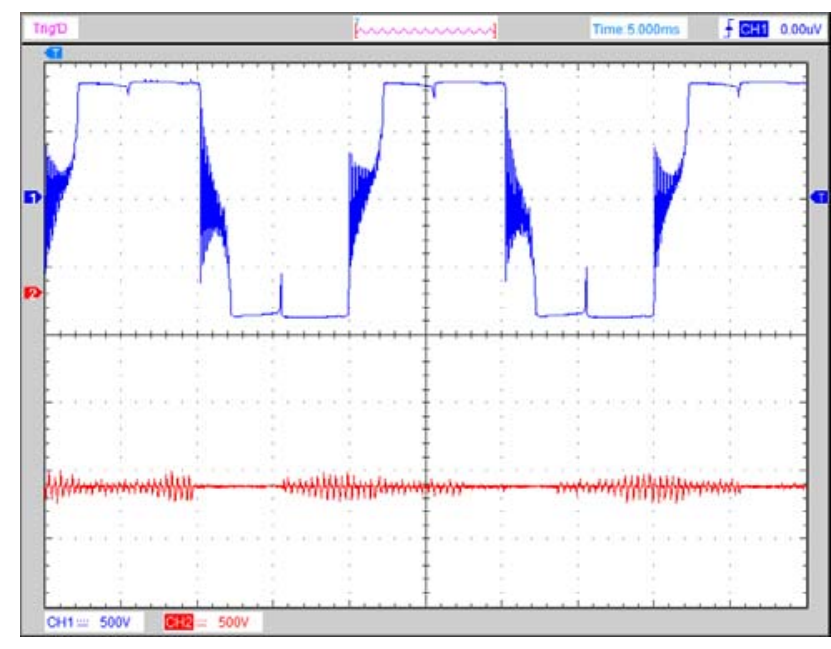

Fig. 9. Dependences of the rotating frequency and current of the $I M$ after optimization

Scientific results, conclusions and recommendations are as follows:

1. Based on analysis of current research it can be concluded that the stability of the electric drive of the lifting mechanism to disturbing torques is provided at the condition of coincidence of zero value of electric drive's electric coordinates and speed of deviation of ship's diametric plane from the vertical position.

2. Criteria for optimizing control system of lifting electric drive are used by mathematical description of its dynamics by differential equations with calculated coefficients derived from the functions of transients.

3. The obtained experimental dependences of coefficients of equations of dynamic object motion under the influence of disturbing forces in the coordinate plane allowed to parameterize characteristic equations to the form providing the solution of the stability problem of the torque on the shaft of the lifting mechanism electrical motor.

4. The developed functional diagram of the automatic control system eliminates the aperiodic components in the control law in compliance with the criteria of stability and quality of transients by applying the regulator for all modes of coordinate characteristics with forcing of overcoming of the dead zone and increasing the stability of the electric drive as a dynamic object.

5. The carried out complex of investigations may find practical implementation in electric drives of ship's lifting mechanisms that will improve their performance, decrease operational and maintenance downtimes.

\section{REFERENCES}

1. Hoffmann C., Radisch C., Werner H. Active damping of container crane load swing by hoisting modulation - An LPV approach. 51st IEEE Conference on Decision and Control (CDC). IEEE, 2012. doi: 10.1109/cdc.2012.6426889.

2. Raubar E., Vrančić D. Anti-sway system for ship-to-shore cranes. Strojniški vestnik (Journal of Mechanical Engineering), 2012, vol.58, no.5, pp. 338-344. doi: 10.5545/sv-jme.2010.127.

3. Skaf J., Boyd S.P. Controller coefficient truncation using Lyapunov performance certificate. International Journal of Robust and Nonlinear Control, 2010, vol.21, no.1, pp. 55-78. doi: 10.1002/rnc.1577.

4. Belunce A., Pandolfo V., Roozbahani H., Handroos H. Novel control method for overhead crane's load stability. Procedia Engineering, 2015, vol.106, pp. 108-125. doi: 10.1016/j.proeng.2015.06.014.

5. Balachandran B., Li Y.-Y., Fang C.-C. A mechanical filter concept for control of non-linear crane-load oscillation. Journal of Sound and Vibration, 1999, vol.228, iss.3, pp. 651-682. doi: 10.1006/jsvi.1999.2440.

6. Alli H., Singh T. Passive control of overhead cranes. Journal of Vibration and Control, 1999, vol.5, no.3, pp. 443-459. doi: $10.1177 / 107754639900500306$.

7. Wua T.-S., Karkoub M., Yu W.-S., Chen C.-T., Her M.-G., Wu K.-W. Anti-sway tracking control of tower cranes with delayed uncertainty using a robust adaptive fuzzy control. Fuzzy Sets and Systems, 2016, vol.290, pp 118-137. doi: 10.1016/j.fss.2015.01.010.

8. Henry R.J., Masoud Z.N., Nayfeh A.H., Mook D.T. Cargo pendulation reduction on ship-mounted cranes via boom-luff angle actuation. Journal of Vibration and Control, 2001, vol.7, no.8, pp. 1253-1264. doi: 10.1177/107754630100700807.

9. Budashko V.V., Onishchenko O.A. Improving management system combined thruster propulsion systems. Bulletin of NTU «KhPI», 2014, no.38(1081), pp. 45-51. (Ukr).

10. Budashko V.V., Onishchenko O.A. Mathematical principles of simulation of power plant's control system at drillship. Bulletin of Kamchatka State Technical University, 2014, no.29, pp. 6-13. (Rus). 11. Budashko V.V., Onischenko O.A., Yushkov E.A. Physical modeling of multi-propulsion complex. Collection of scientific works of the Military Academy (Odessa City), 2014, no.2 pp. 88-92. (Rus).

12. Budashko V.V., Yushkov Y.A. Mathematic modeling of allrange controllers speed of thrusters for ship power plants in combined propulsion complexes. Electronic Modeling, 2015, vol.37, no.2, pp. 101-114. (Rus).

13. Budashko V.V. Implementation approaches during simulation of energy processes for a dynamically positioned ship. Electrical Engineering \& Electromechanics, 2015, no.6, pp.14-19. doi: 10.20998/2074-272X.2015.6.02. (Rus). 
14. A.A. Bojko, V.V. Budashko, E.A. Yushkov, Bojko N.A. Synthesis and research of automatic balancing system of voltage converter fed induction motor currents. Eastern-European Journal of Enterprise Technologies, 2016, vol.1, no.2(79), pp. 22-34. doi: 10.15587/1729-4061.2016.60544.

15. Araya H., Kakuzen M., Kinugawa H., Arai T. Level luffing control system for crawler cranes. Automation in construction, 2004, vol.13, no.5, pp. 689-697. doi: 10.1016/j.autcon.2004.04.011.

\section{Received 24.03.2016}

How to cite this article:

Budashko V.V. Increasing control's efficiency for the ship's two-mass electric drive. Electrical engineering \& electro-

mechanics, 2016, no.4, pp. 34-42. doi: 10.20998/2074-272X.2016.4.05.
V.V. Budashko, Candidate of Technical Science, Associate Professor,

Odessa National Maritime Academy,

8, Didrikhson Str., Odessa, 65029.

phone+380 48 7332367, e-mail: bvv@te.net.ua 